Çanakkale Onsekiz Mart University, Journal of Graduate School of Natural and Applied Sciences, 2016:2, 1, 68-83

\title{
V1095 Her ve V1101 Her Sistemlerinin Dönem Değişimleri
}

\author{
Oğuz ÖZTÜRK ${ }^{1 *}, \quad$ Ahmet ERDEM $^{2}, \quad$ Fahri \\ ALIÇAVUŞ ${ }^{3}$ \\ ${ }^{1}$ Canakkale Onsekiz Mart Üniversitesi, Fen Edebiyat \\ Fakültesi, Fizik ABD, Çanakkale \\ ${ }^{2}$ Canakkale Onsekiz Mart Üniversitesi, Fen Edebiyat \\ Fakültesi, Fizik ABD, Çanakkale \\ ${ }^{3}$ Çanakkale Onsekiz Mart Üniversitesi, Fen Edebiyat \\ Fakültesi, Fizik ABD, Çanakkale
}

\section{Özet}

Şu ana kadar literatürde, her iki sistem üzerine yapılan ne fotometrik ne de tayfsal çalışma bulunmamaktadır. Bu çalışmada, V1095 Her ve V1101 Her sistemlerinin SuperWASP 1ş1k eğrileri ile birlikte dönem değişimleri ilk kez analiz edilmiştir. Sistemlerin parabolik dönem değişimleri, her bir sistem için elde edilen $\mathrm{O}-\mathrm{C}$ verilerine, Zasche ve ark. (2009) tarafindan yazılan MATLAB kodu kullanılarak ağırlıklı en küçük kareler yöntemi ile incelenmiştir. O-C diyagramlarında çevrimsel bir değişim görüldügüünden, aynı MATLAB kodu kullanarak, 1şı1k zaman etkisi (LTE) analizi de yapılmıştır. SuperWASP 1şık eğrileri çözümü için Wilson \& Devinney (1971) kodu kullanılmıştır. V1095 Her ve V1101 Her sistemlerinin O-C diyagramları, sırasıyla, aşağı ve yukarı yönlü parabol

*Sorumlu Yazar (Corresponding Author): Oğuz Öztürk (e-posta: oguzozturk@comu.edu.tr) 
üzerine binmiş sinüzoidal bir değişim göstermektedir. V1095 Her'de düzenli olarak görülen dönem azalma hızı ve V1101 Her'de düzenli olarak görülen dönem artış hızı hesaplanmıştır. Dönem değişimine sebep olabilecek fiziksel mekanizmalar tartışılmıştır. O-C diyagramlarında görülen çevirimsel değişimler LTE ile yorumlanmıştır. Her iki sistemin fotometrik kütle oranları elde edilmiş ve mutlak parametreleri yaklaşık olarak tahmin edilmiştir.

Anahtar Sözcükler: yıldızlar: örten çift yıldızlar: V1095 Her ve V1101 Her

\section{Period Study of V1095 Her and V1101 Her}

\section{Abstract}

So far, there is neither photometric nor spectral study on both of the systems in the literature. SuperWASP light curves and orbital period variations of V1095 Her and V1101 Her were analyzed for the first time in this study. A weighted least-squares method was applied to each O-C data sets by using a MATLAB code given by Zasche et al. (2009) to find their quadratic ephemeris. Since the cyclic O-C variations were seen in the O-C diagrams, the light travel time effect (LTE) analysis were also performed by the same MATLAB code. Wilson \& Deviney (1971) code is used for the SuperWASP light curve solution. The O-C diagrams of V1095 Her and V1101 Her show sinusoidal variations superimposed on a downward parabola and upward parabola, respectively. Rates of secular period decrease of 
V1095 Her and period increase of V1101 Her were calculated. Physical mechanisms which could cause of these period changes were discussed. Cyclic changes in the O-C diagrams were interpreted by means of the LTE. Photometric mass ratio is obtained and approximate absolute parameters of the systems are predicted.

Keywords: stars: binaries: eclipsing stars: individual: V1095 Her and V1101 Her.

\section{Introduction}

V1095 Her (GSC 03098-00683, 2MASS J17280331+4341239, $\mathrm{V}=11.52 \mathrm{mag}$ ) and V1101 Her (GSC 03528-00044, 2MASS $\mathrm{J} 18073325+4654350, \mathrm{~V}=12.08 \mathrm{mag}$ ) were discovered as a variable star by the ROTSE All-Sky Survey (Akerlof et al., 2000). Both systems were also observed by Wide Angle Search for Planets surveys (SuperWASP) with broad-band filters (400$700 \mathrm{~nm}$ ) (Pollacco et al. 2006). Although significant number of minimum times has been given by many authors (see Section 2), there has been no $\mathrm{O}-\mathrm{C}$ based period analysis in the literature so far. Unfortunately, there are neither photometric nor spectroscopic studies on V1095 Her and V1101 Her up to now.

\section{Orbital Period Analysis}

In order to do the $\mathrm{O}-\mathrm{C}$ based period analysis, we first collected all of the minimum times of both systems from the literature. All minimum times which have been published so far were calculated from the CCD and photoelectric observations. All minimum times have different errors ranging from 0.001 to 0.004 days. Therefore, in order to account those errors, we attend 1,5 and 10 weights to minimum times depending on their relative errors. 
Collected minimum times and their adopted weights can be requested from authors. The linear ephemeris used for the O-C diagrams of V1095 Her and V1101 Her are taken from Diethelm (2007) and Diethelm (2006), respectively, and given bellow:

$$
\begin{aligned}
& C_{1, V 1095 \mathrm{Her}}=H J D 2454002.3187+0^{d} .4153778 \times \mathrm{E} \\
& C_{1, \mathrm{~V} 1101 \mathrm{Her}}=H J D 2453620.4894+0^{d} .3826606 \times \mathrm{E}
\end{aligned}
$$

A weighted least-square method was applied to O-C data sets of both systems by using a MATLAB code given by Zasche et al. (2009) to find their quadratic ephemeris. The resulting quadratic ephemeris are derived as follows:

$$
\begin{aligned}
C_{2, \text { V1095 Her }}= & H J D 2454002.3177(7)+0^{d} .4153782(1) \times \mathrm{E} \\
& -1^{d} .2(2) \times 10^{-10} \times \mathrm{E}^{2} \\
C_{2, \text { V1101 Her }}= & H J D 2453620.4905(5)+0^{d} .3826572(1) \times \mathrm{E} \\
& +3^{d} .8(4) \times 10^{-10} \times \mathrm{E}^{2}
\end{aligned}
$$

The parabolic changes seen in the O-C diagrams of V1095 Her and V1101 Her (see Figure 2.1 and 2.2) can be due to the combined effect of mass transfer between components and mass loss from the system. One scenario for these secular period increase or decrease is given by Erdem and Öztürk (2014) based on the paper of Tout and Hall (1991) as follows:

$$
\frac{\dot{P}}{P}=\left[2\left\{\frac{10 R_{2}}{d}\right\}^{2} \frac{M_{1}+M_{2}}{M_{1} M_{2}}-\frac{2}{M_{1}+M_{2}}\right] \dot{M}+\frac{3\left(M_{1}-M_{2}\right)}{M_{1} M_{2}} \dot{M}_{2}
$$

where $M_{1}, M_{2}, R_{2}$ and $d$ are mass of primary star, mass of secondary star, radius of secondary star and distance between the components, respectively. $\dot{M}_{2}=\dot{M}-\dot{M}_{1}<0$ is mass loss rate from the secondary component, $\dot{M}<0$ is the mass loss rate from the system and $\dot{M}_{1}>0$ is the rate of mass transfer from secondary to primary component. 

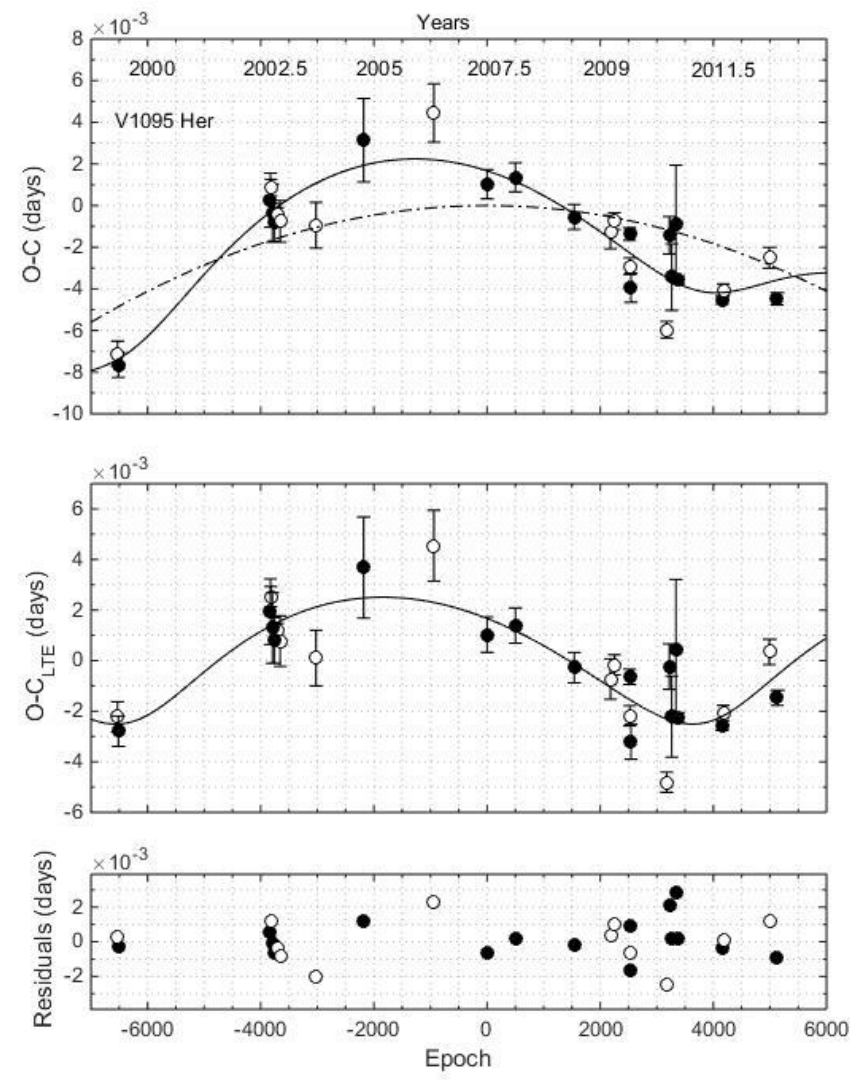

Figure 2.1. O-C diagram of V1095 Her. Upper panel shows the parabolic (dashed line) and sinusoidal variation superimposed on parabolic variation (solid line) while middle and bottom panel show only LTE effect due to the unseen third body and residuals, respectively.

According to this scenario, fractional mass transfer from secondary to primary can be represented by $\beta$, i. e. , $\dot{M}_{1}=-\beta \dot{M}_{2}(0<$ $\beta<1$ ). If the mass transfer is non-conservative, i.e., there are also some mass loss from the system $(\dot{M}<0)$, and the rate of trans- 
ferred mass to the primary component is dominant then the orbital period of the system can increase secularly. On the other hand if the mass transfer is non-conservative and the rate of mass loss from the systems is dominant then the orbital period of the system can decrease. We discuss this scenario in more detail in Section 4.
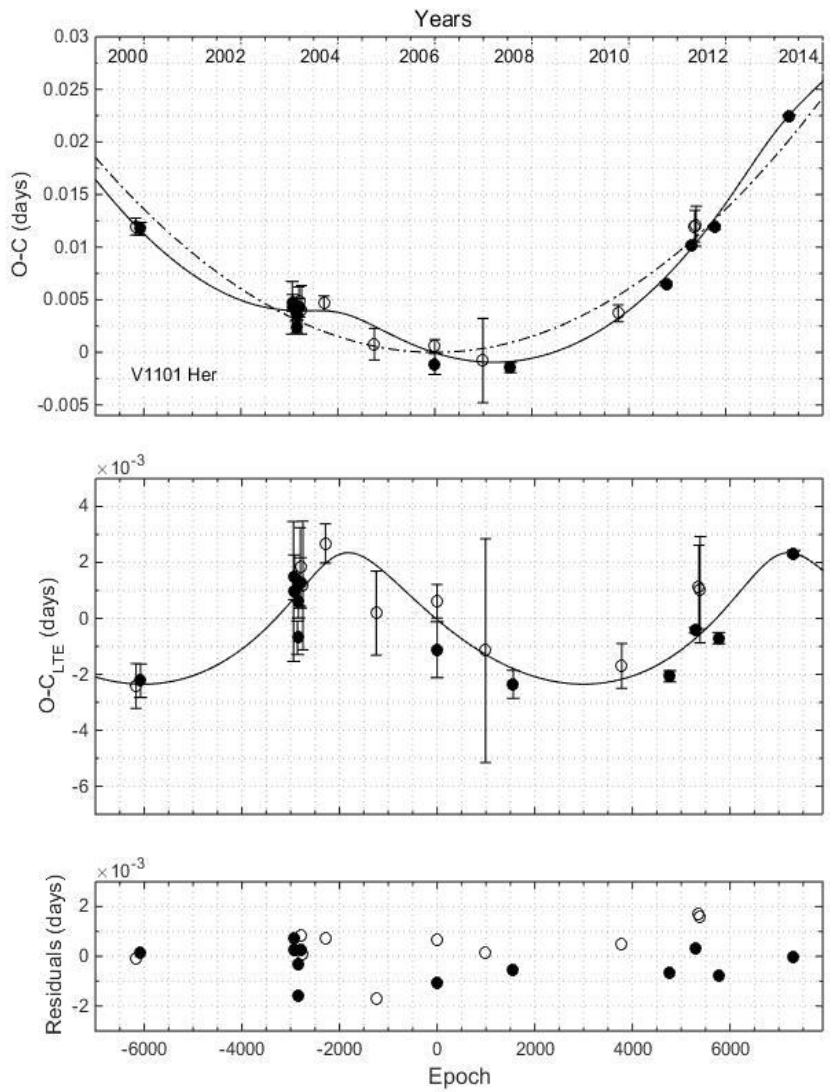

Figure 2.2. Same as Figure 2.1 but for V1101 Her. 
Table 2.1. Parameters derived from O-C analysis of V1095 Her and V1101 Her

\begin{tabular}{|c|c|c|}
\hline Parameters & V1095 Her & V1101 Her \\
\hline$T_{0}(\mathrm{HJD})$ & $2454002.3177(7)$ & $2453620.4905(5)$ \\
\hline$P$ (days) & $0.4153782(1)$ & $0.3826572(1)$ \\
\hline$Q \times 10^{-10}$ (days) & $-1.2(2)$ & $3.8(4)$ \\
\hline$A$ (days) & $0.003(1)$ & $0.0023(7)$ \\
\hline$a_{12} \operatorname{sini}_{12}(\mathrm{AU})$ & $0.43(7)$ & $0.41(8)$ \\
\hline$e_{12}$ & $0.4(2)$ & $0.4(2)$ \\
\hline$\omega_{12}(\mathrm{deg})$ & $290(85)$ & $74(45)$ \\
\hline$P_{12}$ (years) & $12(2)$ & $9.5(7)$ \\
\hline$f_{M_{3}}\left(\mathrm{M}_{\odot}\right)$ & $0.0006(2)$ & $0.0007(2)$ \\
\hline$M_{3}\left(\mathrm{M}_{\odot}\right)$ for $\mathrm{i}=60^{0}$ & $0.10(1)$ & $0.28(9)$ \\
\hline$M_{3}\left(\mathrm{M}_{\odot}\right)$ for $\mathrm{i}=90^{0}$ & $0.08(1)$ & $0.24(5)$ \\
\hline
\end{tabular}

Both of the systems show also sinusoidal variations in their $\mathrm{O}-\mathrm{C}$ diagrams (see Figure2.1 and 2.2). Most likely cause of this sinusoidal variation could be light travel time effect (LTE) due to an unseen third body orbiting around binary star systems. Therefore the LTE equation given by Irwin (1959) was fitted to the O-C residuals in order to get insight about the physical parameters of the respective hypothetical third bodies:

$\Delta \mathrm{t}=\frac{a_{12} \sin i_{12}}{c}\left\{\frac{1-e_{12}^{2}}{1+\cos v_{12}} \sin \left(v_{12}+\omega_{12}\right)+\mathrm{e}_{12} \cos \omega_{12}\right\}$

where $\Delta \mathrm{t}$ is the time delay due to LTE, $c$ is speed of light, $a_{12}, i_{12}, e_{12}, \omega_{12}$ and $v_{12}$ are semi-major axis, inclination, 
eccentricity, longitude of periastron and true anomaly of the position of the eclipsing pair's mass center on the orbit around the unseen third body, respectively. $v_{12}$ includes $P_{12}$ which is the orbital period of the binary star system around the center of mass of the triple system.

\section{Light Curve Analysis}

Both systems were observed by Wide Angle Search for Planets surveys (SuperWASP) with broad-band filters (400-700 nm) (Pollacco et al. 2006). So far there has been no published light curve solution in the literature for these two W UMa type systems. In order to do the light curve analysis the Wilson-Devinney (WD) code (Wilson and Devinney, 1971) was used.

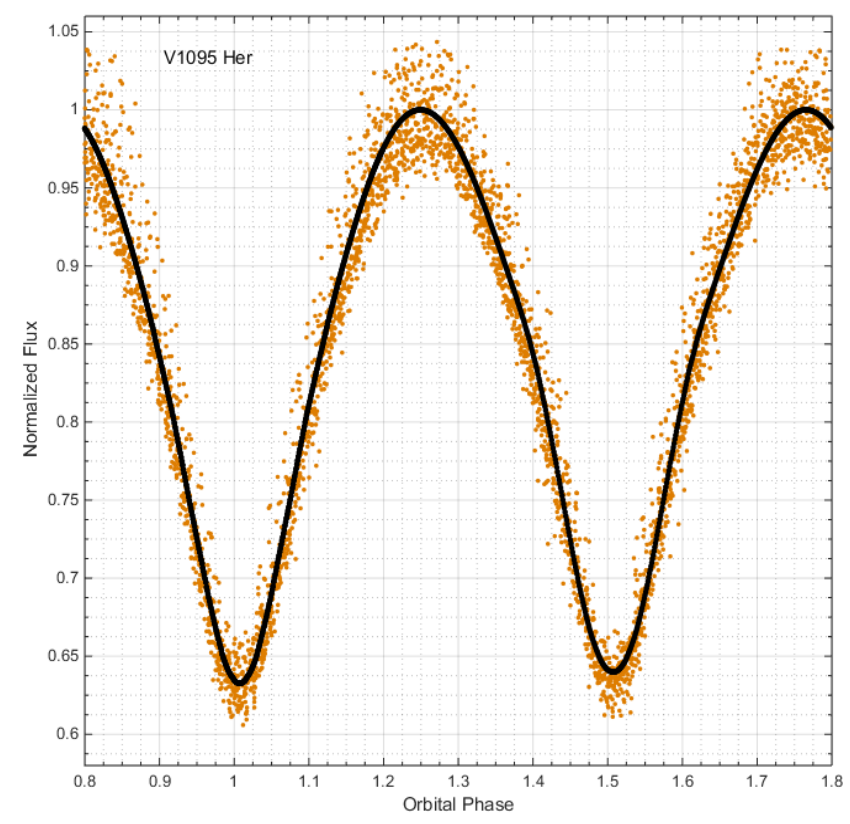

Figure 3.1. Observational points (yellow circle) and best WD fit (solid line) to the SuperWASP light curve of V1095 Her. 
The intrinsic color indices, $(B-V)_{0}$, were computed by using the absolute magnitude calibrations for W UMa stars given by Eker et al. (2009). Effective temperatures of primary components were calculated according to Drilling \& Landolt (2000)'s color index - effective temperature calibration to be $4350 \mathrm{~K}$ and $6950 \mathrm{~K}$ for V1095 Her and V1101 Her, respectively. The bolometric gravity darkening exponents and albedos of the components of both systems were taken to be 0.32 (Lucy, 1967) and 0.50 (Rucinski 1969) for convective atmospheres (T<7200 K), respectively. Orbits of both binary star systems were assumed to be circular in this solution since W UMa type binaries are in contact configurations.

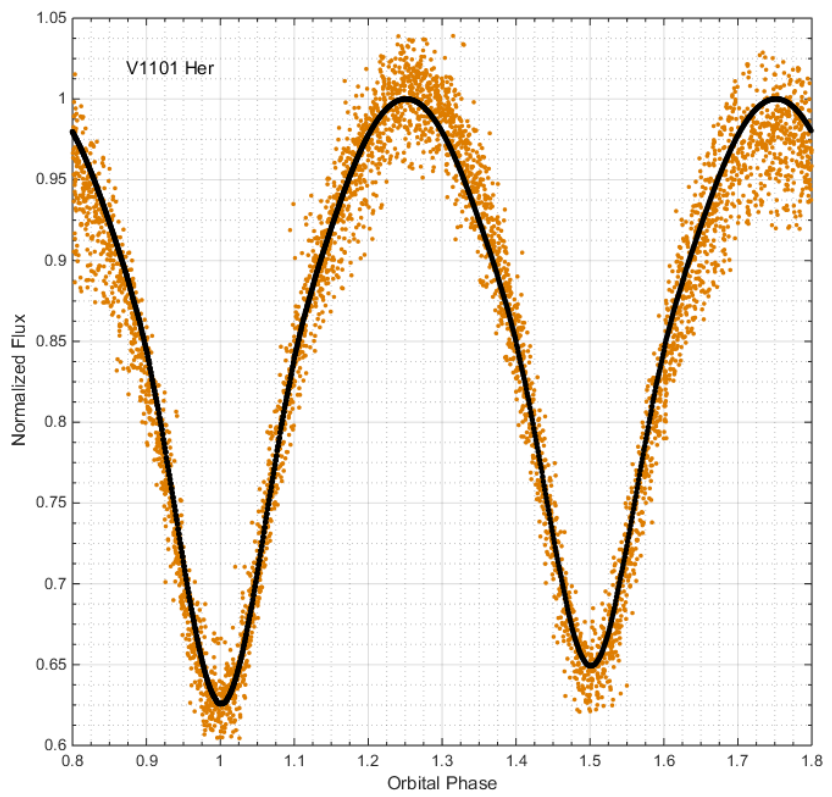

Figure 3.2. Same as Figure 3.1 but for V1101 Her.

The solution was performed in Mod 3 (contact configuration). The mass ratio $(q)$, the orbital inclination $(i)$, the effective 
temperature of secondary component $\left(T_{2}\right)$, the luminosity of primary star $\left(L_{1}\right)$, and the dimensionless potential of primary star $\left(\Omega_{1}=\Omega_{2}\right)$ were adjustable parameters. Since the third light contributions for both of the systems are too small (see Section 4), this contributions were assumed to be zero. Derived parameters from the light curve solutions are given in Table 3.1.

Table 3.1. Parameters derived from light curve analysis of V1095 Her and V1101 Her.

\begin{tabular}{|l|c|c|}
\hline Parameters & V1095 Her & V1101 Her \\
\hline$(B-V)_{0}(\mathrm{mag})$ & $1.2(1)$ & $0.37(5)$ \\
$T_{1}(\mathrm{~K})$ & 4350 & 6950 \\
$T_{2}(\mathrm{~K})$ & $4350(210)$ & $6700(320)$ \\
$i(\mathrm{deg})$ & $74.2(3)$ & $72.19(7)$ \\
$\Omega_{1}$ & $2.461(4)$ & $3.632(3)$ \\
$\Omega_{2}$ & 2.4614 & 3.6317 \\
$q\left(\mathrm{M}_{2} / \mathrm{M}_{1}\right)$ & $0.326(9)$ & $0.97(1)$ \\
$\phi(\mathrm{phase}$ shift $)$ & $0.0074(2)$ & $0.0013(2)$ \\
$L_{1} / L_{T}$ & $0.73(2)$ & $0.54(2)$ \\
$L_{2} / L_{T}$ & 0.273 & 0.462 \\
$e$ & 0 & 0 \\
$\omega(\mathrm{deg})$ & 90 & 90 \\
Filling factor $(\%)$ & 131 & 112 \\
$r_{1, \text { mean }}\left(\mathrm{R}_{1} / \mathrm{d}\right)$ & $0.4945(4)$ & $0.3909(3)$ \\
$r_{2, \text { mean }}\left(\mathrm{R}_{2} / \mathrm{d}\right)$ & $0.3009(4)$ & $0.3845(4)$ \\
\hline
\end{tabular}




\section{Results and Discussions}

Approximate absolute elements derived from light curve analysis are given in Table 4.1. For the derivation we followed following steps: (i) The masses of primary stars were taken from the calibrations of the color index, effective temperature, mass and spectral type for main-sequence stars given by Drilling \& Landolt (2000) in their Table 15.7 and 15.8. (ii) The masses of secondary stars were computed from the photometric mass ratios. (iii) The semi-major axes were derived from Kepler's third law (iv) The radius of both components of the systems were calculated by means of the photometric mean radii and semi-major axes: $R=r_{(i, m e a n)} d(i=1,2)$. (v) The bolometric magnitudes and surface gravity values of the components were calculated by adopting the solar values $\quad\left(T_{\odot}=5771.8 \pm 0.7 \mathrm{~K}\right.$, $M_{b o l, \odot}=4.7554 \pm 0.0004 \mathrm{mag}, g_{\odot}=27423.2 \pm 7.9 \mathrm{~m} / \mathrm{s}^{2}$ from Pecaut \& Mamajek (2013)).

In order to explain the secular period increase and/or decrease seen in the $\mathrm{O}-\mathrm{C}$ diagrams, we considered the non-conservative mass transfer mechanism given by the paper of Erdem \& Öztürk (2014) (see Section 2). In this scenario a relation between $\dot{M}$, $\dot{M}_{1}, \dot{M}_{2}$ and $\beta$, which are defined in Section 2 , is given as follows:

$$
\dot{M} \leq(1-\beta) \dot{M}_{2}=\frac{(\beta-1)}{\beta} \dot{M}_{1}
$$

V1095 Her: Downward parabolic O-C form indicates that the orbital period is continuously decreasing at a rate of $0.017 \mathrm{~s} / \mathrm{yr}$. In case of non-conservative mass transfer mechanism, this observed period decrease indicates that mass loss from the system should be dominant. Moreover, by means of $\mathrm{Eq}(5)$ and $\mathrm{Eq}$ (7), the massloss rate of the system and the mass gain rate of the primary 
component should be in the intervals of $10^{-7}-10^{-9} M_{\odot} / \mathrm{yr}$ and $10^{-}$ ${ }^{6}-10^{-12} M_{\odot} / \mathrm{yr}$, respectively, for $0<\beta<\beta_{\text {cri }}=0.922$, where $\beta_{c r i}$ is the maximum possible value of fractional mass transfer rate from secondary to primary component for systems showing period decrease. Interval of the mass loss rate is almost consistent with the typical rates of mass loss due to stellar wind ( e.g. $10^{-8}-10^{-11} M_{\odot} /$ yr from Hilditch (2001)).

Table 4.1. Derived approximate absolute elements of V1095 Her and V1101 Her.

\begin{tabular}{|lcccc|}
\hline Parameters & \multicolumn{2}{c}{ V1095 Her } & \multicolumn{2}{c|}{ V1101 Her } \\
& Pri. & Sec. & Pri. & Sec. \\
\hline Sp. Type & \multicolumn{2}{c}{ K5V } & \multicolumn{2}{c|}{ F2V } \\
$d\left(\mathrm{R}_{\odot}\right)$ & \multicolumn{2}{c}{$2.25(2)$} & \multicolumn{2}{c}{$3.18(3)$} \\
$M\left(\mathrm{M}_{\odot}\right)$ & $0.67(1)$ & $0.22(1)$ & $1.51(1)$ & $1.46(3)$ \\
$R\left(\mathrm{R}_{\odot}\right)$ & $1.11(1)$ & $0.68(1)$ & $1.25(1)$ & $1.23(1)$ \\
$\log g(\mathrm{cgs})$ & $4.17(1)$ & $4.12(3)$ & $4.43(2)$ & $4.43(2)$ \\
$M_{\text {bol }}(\mathrm{mag})$ & $5.7(2)$ & $6.8(2)$ & $3.5(1)$ & $3.7(1)$ \\
\hline
\end{tabular}

V1101 Her: Upward parabolic O-C form indicates that the orbital period is continuously increasing at a rate of $0.062 \mathrm{~s} / \mathrm{yr}$. By means of Eq (5) and Eq (7), $\beta_{\text {cri }}$, which is the minimum possible value of fractional mass transfer rate from secondary to primary component for systems showing period increase, is found to be $\beta_{\text {cri }}=0.998 \quad\left(\beta_{\text {cri }}=0.998<\beta<1\right)$. We can say that mass transfer from secondary to primary component is almost conservative since $\beta_{c r i}$ is close to unity. In this case, the rate of transferred mass to the primary component, which is the responsible mechanism for this observed period increase, should be $2.77 \times 10^{-5}$ $M_{\odot} / y r$. In case of non-conservative mass transfer, by means of 
Eq (5) and Eq (7), intervals of the rate of transferred mass to the primary component and that of mass loss from the system are calculated to be in the order of $10^{-3}-10^{-5} M_{\odot} / \mathrm{yr}$ and $10^{-6}-10^{-11}$ $M_{\odot} / \mathrm{yr}$, respectively.

If the orbits of the unseen third bodies in V1095 Her and V1101 Her are co-planar with the orbits of their respective eclipsing pairs then their masses and semi-major axes of their orbits should be $0.087 \pm 0.012 M_{\odot}$ and $4.4 \pm 0.8$, AU and $0.25 \pm 0.05 M_{\odot}$ and 4.8 $\pm 0.7 \mathrm{AU}$, respectively. The bolometric magnitudes of third bodies can be calculated from the empirical mass luminosity relation given by Demircan \& Kahraman (1991) to be $12.2 \pm 0.5 \mathrm{mag}$ for V1095 Her and 10.9 1.25 mag for V1101 Her. It is found that the third bodies were $\sim 7$ mag fainter than this two W UMa type binaries. Using the relation of $L \sim M^{3.9}$ between mass and luminosity for main-sequence stars given by İbanoğlu et al. (2006), the light contribution of the third bodies to the total light of the systems were estimated roughly to be 0.03 percent for V1095 Her and 0.05 percent for V1101 Her, which are too small to detect from ground based photometric observations.

\section{Acknowledgement}

This work was partly supported by TUBITAK (Scientific and Technological Research Council of Turkey) for a Doctoral Fellowship Award and makes use of data from the DR1 of the WASP data (Butters et al. 2010) as provided by the WASP consortium, and the computing and storage facilities at the CERIT Scientific Cloud, reg. no. CZ.1.05/3.2.00/08.0144 which is operated by Masaryk University, Czech Republic. We also would like to thank the anonymous referee who provided valuable comments for improving the manuscript. 


\section{References}

Akerlof C., Amrose S., Balsano R., Bloch J., Casperson D., Fletcher S., Gisler G., Hills J., Kehoe R., Lee B., Marshall S., McKay T., Pawl A., Schaefer J., Szymanski J., Wren J., 2000. ROTSE All-Sky Surveys for Variable Stars. I. Test Fields. The Astronomical Journal :119, 1901-1913.

Demircan O., Kahraman G., 1991. Stellar mass-luminosity and mass-radius relations, Astrophysics and Space Science:181, 313-322.

Diethelm R., 2006, 165. List of Timings of Minima Eclipsing Binaries by BBSAG Observers, Information Bulletin on Variable Stars: 5713.

Diethelm R., 2007, 166. List of Timings of Minima Eclipsing Binaries by BBSAG Observers, Information Bulletin on Variable Stars: 5781.

Drilling J.S., Landolt A.U., 2000. Allens Astrophysical Quantities. In: Cox, A. N. Ed. , fourth ed. AIP Press, Springer, New York: 388-389.

Eker Z., Bilir S., Yaz E., Demircan O., Helvac1 M., 2009. New absolute magnitude calibrations for W Ursa Majoris type binaries. Astronomische Nachrichten; 330, 68-76. 
Erdem A., Öztürk O., 2014. Non-conservative mass transfers in Algols. Monthly Notices of the Royal Astronomical Society :441, 1166-1176.

Hilditch R.W., 2001. An Introduction to Close Binary Stars. Cambridge, UK: Cambridge University Press,

Irwin J.B., 1959. Standard light-time curves. Astronomical Journal: 64, 149-155.

İbanoğlu C., Soydugan F., Soydugan E., Dervisoğlu A., 2006. Angular momentum evolution of Algol binaries. Monthly Notices of the Royal Astronomical Society; 373, 435-448.

Lucy L.B., 1967. Gravity-Darkening for Stars with Convective Envelopes. Zeitschrift für Astrophysik: 65, 89-92.

Pecaut M.J., Mamajek E.E., 2013. Intrinsic Colors, Temperatures, and Bolometric Corrections of Pre-main-sequence Stars. The Astrophysical Journal Supplement: 208, 9-30.

Pollacco D. L., Skillen I., Collier C. A., Christian D. J., Hellier C., Irwin J., Lister T. A., Street R. A., West R. G., Anderson D. R., Clarkson W. I.., Deeg H., Enoch B., Evans A., Fitzsimmons A., Haswell C. A., Hodgkin S., Horne K., Kane S. R., Keenan F. P., Maxted P. F. L., Norton A. J., Osborne J., Parley N. R., Ryans R. S. I., Smalley B., Wheatley P. J., Wilson D. M., 2006. The WASP Project 
and the SuperWASP Cameras. The Publications of the Astronomical Society of the Pacific: 118, 1407-1418.

Rucinski S.M., 1969. The Proximity Effects in Close Binary Systems. II. The Bolometric Reflection Effect for Stars with Deep Convective Envelopes. Acta Astronomica: 19, 245-255.

Tout C. A., Hall D. S., 1991. Wind driven mass transfer in interacting binary systems. Monthly Notices of the Royal Astronomical Society: 253, 9-18.

Wilson R. E., Devinney E. J., 1971. Realization of Accurate Close-Binary Light Curves: Application to MR Cygni. Astrophysical Journal :166, 605-619.

Zasche P., Liakos A., Niarchos P., Wolf. M., Manimanis V., Gazeas K., 2009. Period changes in six contact binaries: WZ And, V803 Aql, DF Hya, PY Lyr, FZ Ori, and AH Tau. New Astronomy 14: 121-128. 